\title{
ANALISA PENUKAR KALOR AFTERCOOLER TYPE SHELL AND TUBE DENGAN METODE DELAWARE DAN WILL JOHNSTON
}

\author{
Akhmad Afandiyanto1, Mulfi Hazwi ${ }^{2}$, Andianto Pintoro ${ }^{3}$, Pramio G. Sembiring ${ }^{4}$ \\ 1,2,3,4 Departemen Teknik Mesin, Fakultas Teknik, Universitas Sumatera Utara \\ Email: achamadafandiyanto@yahoo.com
}

\begin{abstract}
ABSTRAK
Fenomena perpindahan panas dari material atau fluida yang mempunyai temperatur tinggi ke material atau fluida yang mempunyai temperatur rendah.Dalam dunia industri fenomena perpindahan panas tersebut dimanfaatkan untuk keperluan proses dengan menggunakan suatu alat yang biasa disebut sebagai penukar panas atau heat exchanger. tujuan dari penelitian ini adalah untuk memperoleh desain heat exchanger yang paling optimal. Penelitian dilakukan di PT. ANEKA GAS INDUSTRI. Penggunaan metode Delaware dan metode Wills and Johnstone dalam perhitungan perpindahaan panas untuk membandingkan hasil perhitungan dua metode tersebut sehingga diperoleh metode yang paling baik dalam perhitugan perpindahan panas untuk fluida di dalam shell and tube. Dari hasil analisa didapat Koefisien perpindahan panas total dengan metode Delaware 709,12 W/ $\mathrm{m}^{2} . K$ lebih besar 79,6 \% dibandingkan koefisien perpindahan panas total yang dibutuhkan $U_{\text {used }} 394,8 \mathrm{~W} / \mathrm{m}^{2} . K$ sedangkan koefisien perpindahan panas total dengan metode Wills and Johnston $679,36 \mathrm{~W} / \mathrm{m}^{2} . K$ lebih besar $72 \%$ di bandingkan koefisien $U_{\text {used }}$ yang dibutuhkan. Dari hasil perhitungan koefisien perpindahan panas dan penurunan tekanan ke dua metode tersebut dianggap sesuai untuk analisis perpindahan panas pada heat exchanger tipe shell and tube.
\end{abstract}

Kata kunci : Heat exchanger, after cooler, koefisien.

\section{PENDAHULUAN}

Fenomena perpindahan panas dari material atau fluida yang mempunyai temperatur tinggi ke material atau fluida yang mempunyai temperature rendah. Dalam dunia industri fenomena perpindahan panas tersebut dimanfaatkan untuk keperluan proses dengan menggunakan suatu alat yang biasa disebut sebagai penukar panas atau heat exchanger.

Analisa ini akan menggunakan dua metode perhitungan perpindahan panas untuk heat exchanger tipe shell and tube, yaitu metode Bell Delaware dan metode Wills and Johnston. Metode-metode tersebut digunakan untuk menganalisis perpindahan panas dan aliran fluida di dalam shell.

Analisa ini difokuskan pada analisa heat exchanger di suatu perusahaan yang digunakan sebagai aftercooler kompresor atau pendingin udara hasil kompresi yang akan didistribusikan ke alat-alat dan instrumen lain pada perusahaan tersebut. Saat ini, heat exchanger yang digunakan menunujukkan kinerja yang kurang memuaskan, dimana terjadi laju pengotoran atau fouling yang tinggi, serta temperature udara keluar heat exchanger lebih tinggi dari yang diharapkan.

Analisa heat exchanger ini, fluida pendingin yang digunakan adalah air. Air tersebut dialirkan di dalam shell, sedangkan udara dari kompresor dialirkan di dalam susunan pipa-pipa atau tube. 


\section{TINJAUAN PUSTAKA}

\section{Pengertian Heat Exchanger}

Heat exchanger atau dalam bahasa Indonesia disebut sebagai penukar panas merupakan alat yang digunakan untuk menghasilkan proses pepindahan panas antara dua fluida yang memiliki beda temperatur. Panas berpindah dari fluida yang lebih panas ke fluida yang lebih dingin. Jenis penukar panas yang paling sederhana adalah sebuah wadah dimana fluida yang panas dan fluida yang dingin dicampur secara langsung. Dalam sistem demikian kedua fluida akan mencapai temperatur akhir yang sama, dan jumlah panas yang berpindah dapat diperkirakan dengan mempersamakan energi yang dilepas oleh fluida yang lebih panas dengan energi yang diterima oleh fluida yang lebih dingin. Jenis heat exchanger yang lebih umum dipakai adalah heat exchanger dimana satu fluida terpisah dari fluida lainnya oleh satu dinding atau sekat yang dilalui oleh panas. Seperti terlihat pada gambar 1 Heat exchanger jenis ini disebut rekuperator[1].

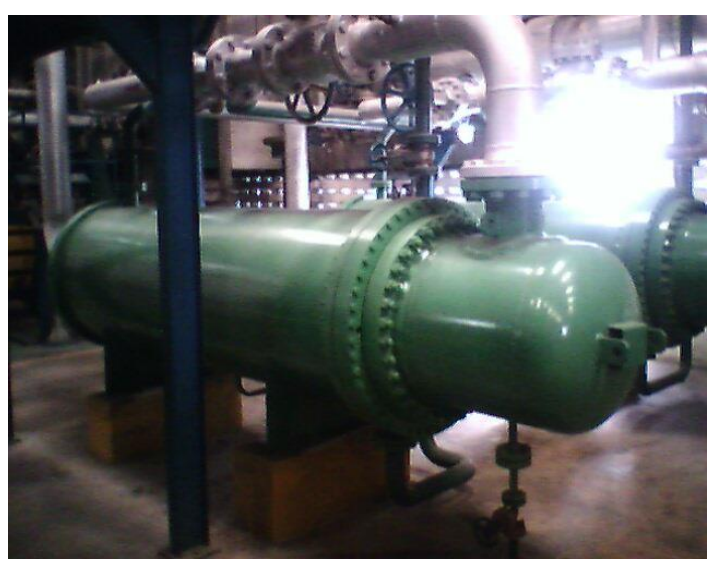

Gambar 1 heat exchanger after cooler

Saat ini, heat exchanger yang digunakan menunujukkan kinerja yang kurang memuaskan, dimana terjadi laju pengotoran atau fouling yang tinggi, serta temperature udara keluar heat exchanger lebih tinggi dari yang diharapkan.

\section{Klasifikasi heat exchanger}

Heat exchanger diklasifiksikan menjadi beberapa kelompok pengelompokan penukar panas didasarkan pada beberapa kriteria, yaitu :

1. Recuperation atau regeneration

Pada rekuperator yang ditunjukkan oleh gambar 2 proses perpindahan panas terjadi diantara dua fluida yang mengalir. Proses perpindahan panas terjadi secara kontinyu, baik melalui dinding yang memisahkan aliran maupun melalui permukaan diantara aliran (kontak langsung)[1].

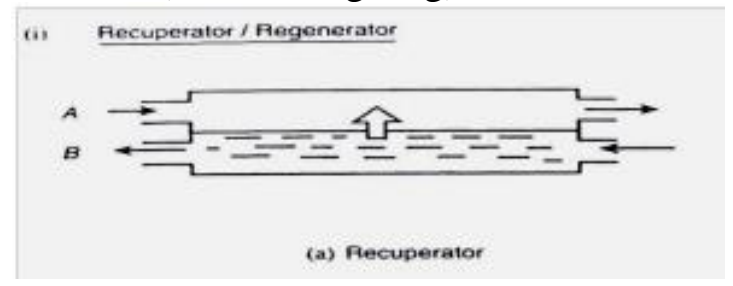

Gambar 2 recuperator.[1] 
2. Perpindahan panas kontak langsung atau transmural

Pada gambar 3 heat exchanger tipe kontak langsung tidak terdapat dinding pemisah antara aliran fluida dingin dan aliran fluida panas sehingga terjadi kontak langsung antara dua fluida tersebut dan membentuk suatu permukaan perpindahan panas[1].

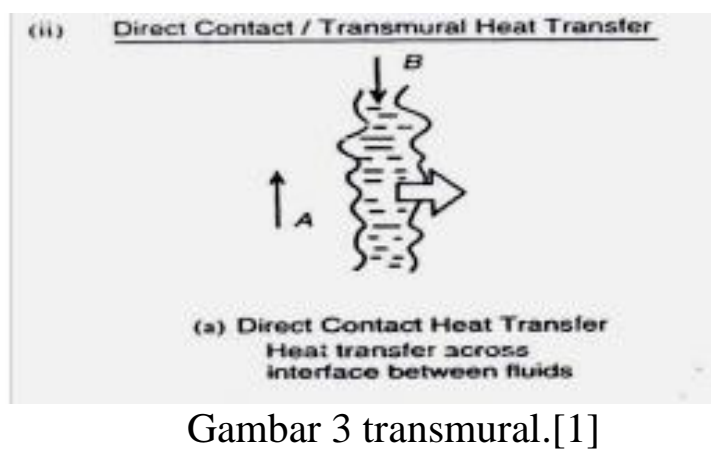

3. Satu fase atau dua fase

Evaporasi atau kondensasi yang terjadi pada salah satu maupun kedua aliran pada heat exchanger dua fase merupakan hal yang kompleks apabila dibandingkan dengan heat exchanger satu fase yang di perlihat kan pada gambar 4[1].

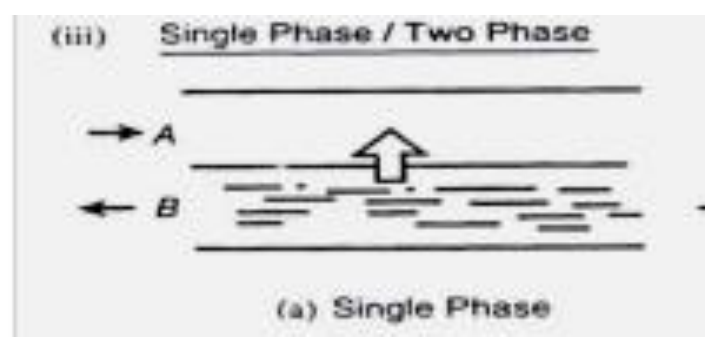

Gambar 4 single phase.[1]

4. Geometri

Pada gambar 5 ukuran dan bentuk heat exchanger sangat bervariasi tergantung dari kebutuhan dan fungsinya[1].

(iv)

Geometry

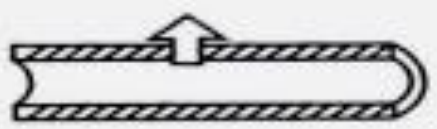

(a) Tubes

Gambar 5 gemetri.[1]

\section{Kebaikan-kebaikan Heat Exchanger Tipe Shell and Tube}

Walaupun dewasa ini sangat banyak jenis heat exchanger yang dikembangkan pada industri-industri, namun heat exchanger jenis shell and tube ini masih jauh lebih banyak digunakan dibanding dengan jenis lainnya. Hal ini adalah diakibatkan beberapa keuntungan yang diperoleh, antara lain adalah : 
Mempunyai lay-out mekanik yang baik, bentuknya cukup baik untuk operasi bertekanan.

$>$ Menggunakan teknik fabrikasi yang sudah mapan (well-established)

$>$ Mudah membersihkannya.

$>$ Prosedur perencanaannya sudah mapan.

$>$ Konstruksinya sederhana, pemakaian ruangan relatif kecil.

$>$ Konstruksinya dapat dipisah-pisah satu sama lain, tidak merupakan satu kesatuan yang utuh, sehingga pengangkutannya relatif gampang.[2]

\section{Prinsip kerja heat exchanger shell and tube}

Prinsip kerja heat exchanger tipe shell and tube adalah perpindahan panas yang terjadi antara permukaan material baik padat maupun cair dengan aliran fluida yang bergerak di sekitarnya akibat adanya perbedaan temperature perpindahan panas konveksi ini dapat dibedakan menjadi dua jenis berdasarkan aliran fluidanya

1. konveksi alamiah

perpidahan panas yang terjadi tanpa adanya bantuan dari luar

2. konveksi paksa

perpindahan panas yang terjadi karena aliran fluida yang mengalir di timbulkan factor dari luar, misalnya dari kipas atau pompa

proses perpindahan panas secara konveksi merupakan perpindahan panas yang paling kompleks karena banyak sekali variabel - variabelnya [2]

\section{METODE ANALISA}

\section{Logaritmic Mean Temperature Difference (LMTD)}

Kasus heat exchanger aliran berlawanan murni gambar 6 adalah Panas berpindah dari suatu fluida panas pada temperatur $T_{h}$ menuju fluida dingin pada temperatur $\mathrm{T}_{\mathrm{c}}$, dimana fluida yang satu mengalir dalam arah yang berlawanan terhadap fluida lainnya[2]

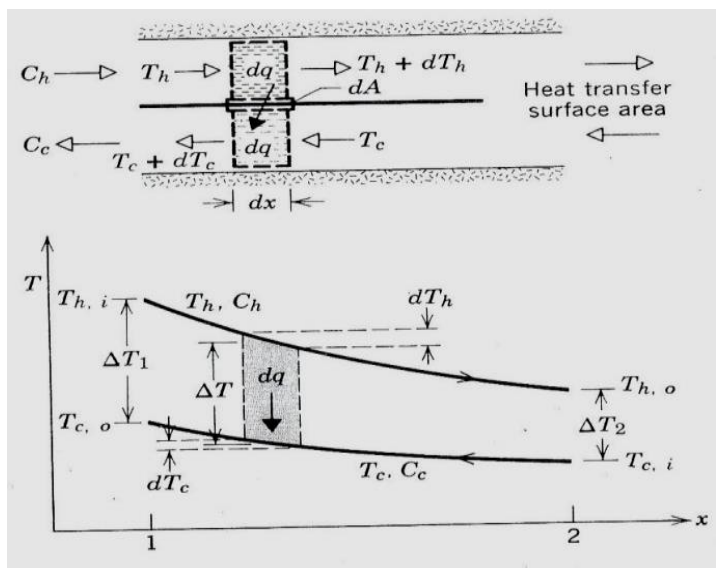

Gambar 6 Heat Exchanger Aliran Berlawanan Murni.[3]

Pada kasus heat exchanger aliran berlawanan murni, perbedaan temperatur rata-rata disebut sebagai logarithmic mean temperatur difference $\Delta T_{L M}$ yang dinyatakan sebagai.

$$
\Delta T_{M}=\Delta T_{L M}=\frac{\|\left(T_{h, \text { in }}-T_{c, \text { out }}\right)-\left(T_{h, \text { out }}-T_{c, \text { in }}\right) \mid}{\ln \left[\left(T_{h, \text { in }}-T_{c, \text { out }}\right) /\left(T_{h, \text { out }}-T_{c, \text { in }}\right)\right]^{[3]}}
$$




\section{Metode Bell Dellaware}

Bell-Delaware menemukan metode perhitungan perpindahan panas dan penurunan tekanan untuk aliran fluida di dalam shell dengan menggunakan beberapa faktor koreksi. Faktor-faktor tersebut meliputi :

1. Kebocoran yang melalui celah anatar tube dan baffle serta celah antara baffle and shell

2. Aliran yang melalui celah antar tube bundle dan shell

3. Efek dari konfigurasi baffle

4. Efek kerugian gradient temperatur dalam perpindahan panas pada aliaran laminar.

Dengan Koefisien perpindahan panas di sisi shell $\left(\alpha_{0}\right)$ yang dinyatakan sebagai

$$
\alpha_{0}=\alpha_{c} . J_{C} . J_{L} . J_{B}
$$

Dimana :

$J_{L}=$ faktor koreksi karena adanya celah antara shell

$J c=$ Faktor koreksi untuk konfigurasi baffle

$J_{B}=$ faktor koreksi akibat aliran bypass

$\alpha_{c}=$ koefisien perpindahan panas aliran menyilang.[3]

\section{Metode Will johnstone}

Gambar 7 menunjukkan fluida mengalir dari A ke B dengan berbagai rute yang masing-masing ditandai dengan subscript. Kebocoran-kebocoran terjadi antara tube dan baffle ( $t$ ), antara baffle dan shell ( $s$ ), bagian aliran menyilang yang melewati tube (c), serta bagian aliran bypass di luar bundle $(b)$. Aliran menyilang dan bypass bersatu membentuk aliran yang melalui celah di luar baffle-cut (w).[3]

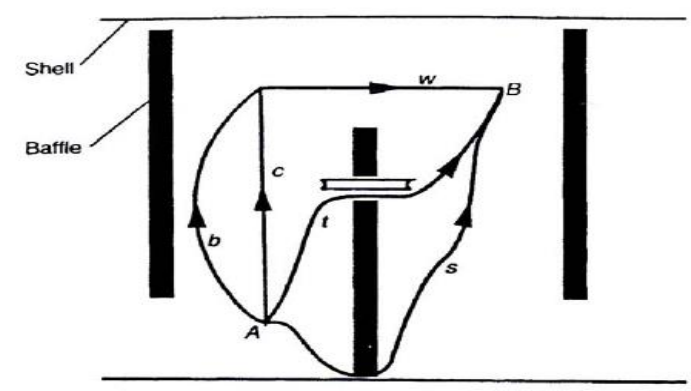

Gambar 7 Aliran-aliran Berdasarkan Metode Wills and Johstone.[4]

Perhitungan koefisien perpindahan panas pada metode ini adalah sebagai berikut

$$
\alpha=\frac{N_{u} \lambda}{D_{0}}=\frac{\lambda}{D_{0}}\left(a \operatorname{Re}^{m} \operatorname{Pr}^{0,34}\right)[4]
$$

dimana $a=0,273$ dan $m=0,635$ untuk susunan staggered tube banks dan bilangan Reynolds $3 \times 10^{2}<\operatorname{Re} \leq 2 \times 10^{5}$

Koefisien perpindahan panas total $(U)$ yang merupakan jumlah dari seluruh koefisien perpindahan panas pada metode bell Delaware will johnstone dapat dihitung dari persamaan

$$
\frac{1}{U}=\frac{1}{h_{o}}+r_{o}+r_{w}+r_{i}\left(\frac{A_{o}}{A_{i}}\right)+\frac{1}{h_{i}}\left(\frac{A_{o}}{A_{i}}\right) \text { [4] }
$$

dimana $h_{o}$ dan $h_{i}$ adalah koefisien perpindahan panas untuk kedua metode, $r_{o}$ dan $r_{i}$, adalah tahanan termal akibat pengotoran aliran fluida, serta $r_{w}$ adalah tahanan termal dinding tube. $A_{o}$ dan $A_{i}$ adalah luas permukaan luar dan dalam tube. 
Persamaan dasar yang digunakan untuk menghitung laju perpindahan panas dalam heat exchanger adalah :

Dimana

$$
\mathrm{Q}=\mathrm{U} . \mathrm{A} . \Delta \mathrm{T} \quad[5]
$$

$\mathrm{Q}=$ laju perpindahan panas total

$\Delta \mathrm{T}=$ perbedaan temperatur

$\mathrm{A}=$ luas permukaan perpindahan panas

$\mathrm{U}=$ koefisien perpindahan panas total. Luas permukaan perpindahan panas diperoleh dari :

Dimana

$$
\mathrm{A}=\mathrm{n} .(\pi . \mathrm{D} . \mathrm{L}) \quad[5]
$$

$\mathrm{N}=$ jumlah tube

$\mathrm{L}=$ panjang tube

Karena luas perpindahan panas yang dipilih sebagai referensi adalah luas permukaan luar tube, maka diameter D yang digunakan adalah diameter luar tube.

Berdasarkan hukum keseimbangan energi, panas yang dilepaskan oleh fluida panas harus sama dengan panas yang diterima fluida dingin sehingga laju perpindahan panas total yang terjadi adalah :

$$
\begin{aligned}
& Q=M_{h} C_{p h}\left(T_{h, \text { in }}-T_{h, \text { out }}\right) \\
& =M_{c} C_{p c}\left(T_{c, \text { out }}-T_{c, \text { in }}\right)
\end{aligned}
$$

subscript $h$ dan $c$ masing-masing mempresentasikan fluida panas dan fluida dingin. $M_{h}$ dan $M_{c}$ adalah laju aliran massa masing-masing fluida, $\mathrm{T}_{\mathrm{h} \text {,in }}$ dan $\mathrm{T}_{\mathrm{c} \text {,in }}$ adalah temperatur masuk masing-masing fluida. $\mathrm{T}_{\mathrm{h} \text {,out }}$ dan $\mathrm{T}_{\mathrm{c}, \text { out }}$ adalah temperatur keluar masing-masing fluida, serta $c_{p h}$ dan $c_{p c}$ adalah kapasitas panas spesifik masing-masing fluida.[6]

\section{HASIL ANALISA}

Gambar dibawah memperlihatkan diagram proses pada aftercooler kompresor. Sebagai input data dalam analisa heat exchanger, data-data yang diketahui adalah

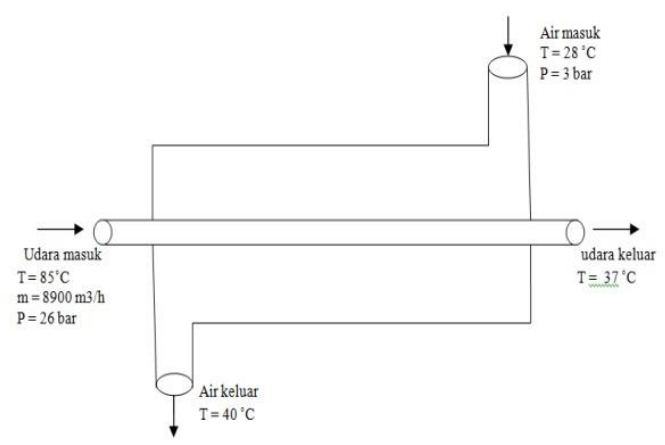

1. Fluida pada sisi tube : Udara bertekanan

i. Komposisi udara masuk

$m_{u}=8900 \mathrm{~m}^{3} / \mathrm{h}$

ii. Temperatur udara masuk, $T u_{, i}=85^{\circ} \mathrm{C}$

iii. Temperatur udara keluar, $T u_{, o}=37{ }^{\circ} \mathrm{C}$

iv. Tekanan udara masuk, $p_{l}=2,6 \mathrm{MPa}=26 \mathrm{bar}$

2. Fluida pada sisi shell : Air

i. Temperatur air masuk, $T_{a, i}=28{ }^{0} \mathrm{C}$

ii. Tekanan air masuk, $p_{w}=0,30 \mathrm{MPa}=3 \mathrm{bar}$

iii. Temperatur air keluar, $T_{a, o}=40{ }^{\circ} \mathrm{C}$ 
Parameter analisa ini berdasarkan survey yang dilakukan di PT. Aneka Gas Industri Region I Sumatera Utara

a. Komposisi udara masuk

1. Laju aliran udara kering

$: 8900 \mathrm{~m}^{3} / \mathrm{h}$

2. Temperatur udara masuk

$: 85^{\circ} \mathrm{C}$

3. Temperatur udara keluar

$: 37^{0} \mathrm{C}$

4. Tekanan masuk

$: 2,6 \mathrm{MPa}=26$ bar

b. Komposisi air masuk

1. Tekanan air masuk

2. Temperatur air masuk

$: 0,30 \mathrm{Mpa}=3 \mathrm{bar}$

3. Temperatur air keluar

$: 28{ }^{0} \mathrm{C}$

4. Laju massa aliran air $m_{a}$

$: 40{ }^{0} \mathrm{C}$

Sifat-sifat udara didapat dari tabel heat transfer dengan data-data sebagai berikut

$$
\begin{array}{cl}
P=26 \mathrm{bar}=2600 \mathrm{kPa} & R=0,287 \mathrm{kPa} \cdot \mathrm{m}^{3} / \mathrm{kg} \cdot \mathrm{K} \\
T=85{ }^{0} \mathrm{C}=358 \mathrm{~K} & 2600 \mathrm{kPa} \\
\rho=\frac{P}{R T}=\frac{\mathrm{kPa} \cdot \mathrm{m}^{3} / \mathrm{kg} \cdot \mathrm{K} \cdot 358}{0,287 \mathrm{~kg} / \mathrm{m}^{3}} \quad \text { Maka laju aliran massa udara : } \\
m_{u}=\rho \cdot v=25,31 \mathrm{~kg} / \mathrm{m}^{3} \cdot 8900 \mathrm{~m}^{3} / \mathrm{hr} \\
=225259 \mathrm{~kg} / \mathrm{hr}=62,5 \mathrm{~kg} / \mathrm{s}
\end{array}
$$

\section{Analisis Kesetimbangan Energi}

1. Laju perpindahan panas aktual yang terjadi di dalam heat exchanger pada sisi tube adalah :

$$
\dot{Q}=\dot{m}_{h} \cdot C p_{h} \cdot\left(T_{h, \text { in }}-T_{h, \text { out }}\right)
$$

Panas spesifik udara kering diperoleh dari temperatur rata-rata udara :

$T=\frac{T_{u, \text { in }}+T_{u, \text { out }}}{2}=\frac{85+37^{0}}{2} \mathrm{C}=61^{\circ} \mathrm{C}=334^{\circ} \mathrm{K}$

Sehingga panas spesifik udara $\left(C p_{h}\right)=1,007 \mathrm{~kJ} / \mathrm{kg} . \mathrm{K}$ Jadi, laju perpindahan panas

yang terjadi adalah: $\dot{Q}=m_{h} \cdot C p_{h} \cdot\left(T_{h, \text { in }}-T_{h, o u t}\right)$

$$
=62,5 \mathrm{~kg} / \mathrm{s} \cdot 1,007 \mathrm{~kJ} / \mathrm{kg} \cdot \mathrm{K} \cdot(358-310) \mathrm{K}=3021 \mathrm{~kW}
$$

2. Laju perpindahan panas maksimal rata-rata yang terjadi di dalam heat exchanger adalah :

$$
Q=\dot{m}_{h} \cdot C p_{h} . \Delta T=\dot{m}_{c} C p_{c} \Delta T_{c}
$$

Panas spesifik $\left(C p_{h}\right)$ udara pada temperatur rata-rata :

$$
\begin{aligned}
& T=\frac{T_{u, \text { in }}+T_{u, \text { out }}}{2}=\frac{85+37}{2}{ }^{0} \mathrm{C}=61^{0} \mathrm{C}=334 \mathrm{~K} \\
& C p_{h}=1,007 \mathrm{~kJ} / \mathrm{kg} . \mathrm{K}
\end{aligned}
$$

Panas spesifik air $\left(C p_{c}\right)=4,18 \mathrm{~kJ} / \mathrm{kg} . K$ 
Maka : $\begin{aligned} C_{h} & =\dot{m}_{h} \cdot C p_{h}=61 \mathrm{~kg} / \mathrm{s} \cdot 1,007 \mathrm{~kJ} / \mathrm{kg} \cdot \mathrm{K} \\ & =61,42 \mathrm{~kW} / \mathrm{K}\end{aligned}$ Oleh karena itu $C_{\min }=C_{h}=61,42 \mathrm{~kW} / \mathrm{K}$
$C_{c}=\dot{m}_{c} \cdot C p_{c}=9,76 \mathrm{~kg} / \mathrm{s} \cdot 4,18 \mathrm{~kJ} / \mathrm{kg} \cdot \mathrm{K}=40,7 \mathrm{~kW} / \mathrm{K}$

Jadi laju perpindahan panas maksimum rata-rata adalah

$Q_{\max }=C_{\min } \cdot\left(T_{h, i n}-T_{c, i n}\right)$

$=61,42 \mathrm{~kW} / \mathrm{K} \cdot(358-301) \mathrm{K}=3500,9 \mathrm{~kW}$

Efektivitas heat exchanger :

$\varepsilon=\frac{Q}{Q_{\max }}=\frac{3021 \mathrm{~kW}}{3500,9 \mathrm{~kW}}=0,86$

\section{Koefisien Perpindahan Panas Total Hasil analisa}

1. Koefisien Perpindahan Panas Total Yang Dibutuhkan

Pengaruh tebal dinding pipa (tube) :

tebaldinding pipa $=D_{o}-D_{i}$

$$
\begin{aligned}
& U=\frac{1}{\frac{1}{h_{i}}+\frac{1}{h_{o}}+\text { pengaruh tebal dinding pipa }} \\
& U=\frac{1}{\frac{1}{2092,7 \mathrm{~W} / \mathrm{m}^{2} \cdot K}+\frac{1}{3919,6 \mathrm{~W} / \mathrm{m}^{2} . K}+\left(1,8 \times 10^{-3}\right)} \\
& U=394,80 \mathrm{~W} / \mathrm{m}^{2} . K
\end{aligned}
$$$$
=12,7 \times 10^{-3}-10,9 \times 10^{-3}
$$$$
=1,8 \times 10^{-3}
$$

2. Berdasarkan hasil perhitungan metodedellaware

$$
\begin{aligned}
& \frac{1}{U}=\frac{1}{h_{o}}+r_{o}+r_{w}+r_{i}\left(\frac{D_{o}}{D_{i}}\right)+\frac{1}{h_{i}}\left(\frac{D_{o}}{D_{i}}\right) \\
& \frac{1}{U}=\frac{1}{11324,1 \mathrm{~W} / \mathrm{m}^{2} \cdot K}+0,0002 \mathrm{~m}^{2} K / \mathrm{W}+4,43 \times 10^{-5} \mathrm{~m}^{2} K / W+ \\
& 0,0004 \mathrm{~m}^{2} K / \mathrm{W}\left(\frac{0,0127 \mathrm{~m}}{0,0109 \mathrm{~m}}\right)+\frac{1}{2092,7 \mathrm{~W} / \mathrm{m}^{2} \cdot K}\left(\frac{0,0127 \mathrm{~m}}{0,0109 \mathrm{~m}}\right) \\
& U=709,12 \mathrm{~W} / \mathrm{m}^{2} \cdot K
\end{aligned}
$$

3. Berdasarkan hasil perhitungan metode Wills and Johnston

$$
\begin{aligned}
& \frac{1}{U}=\frac{1}{h_{o}}+r_{o}+r_{w}+r_{i}\left(\frac{D_{o}}{D_{i}}\right)+\frac{1}{h_{i}}\left(\frac{D_{o}}{D_{i}}\right) \\
& \frac{1}{U}=\frac{1}{6978,1 \mathrm{~W} / \mathrm{m}^{2} . K}+0,0002 \mathrm{~m}^{2} \mathrm{~K} / W+4,43 \times 10^{-5} \mathrm{~m}^{2} \mathrm{~K} / W+ \\
& 0,0004 m^{2} K / W\left(\frac{0,0127 m}{0,0109 m}\right)+\frac{1}{2092,7 W / m^{2} \cdot K}\left(\frac{0,0127 m}{0,0109 m}\right) \\
& U=679,36 \mathrm{~W} / \mathrm{m}^{2} . K
\end{aligned}
$$

Dimana

1. Fouling resistance pada sisi tube

Fluida di dalam tube adalah udara bertekanan sehingga :

$$
r_{i}=0,0004 \mathrm{~m}^{2} \mathrm{~K} / \mathrm{W} \quad \text { [7] }
$$

2. Fouling resistance pada sisi shell 
Fluida di dalam shell adalah air sumur sehingga :

$$
r_{o}=0,0002 \mathrm{~m}^{2} \mathrm{~K} / \mathrm{W} \quad \text { [7] }
$$

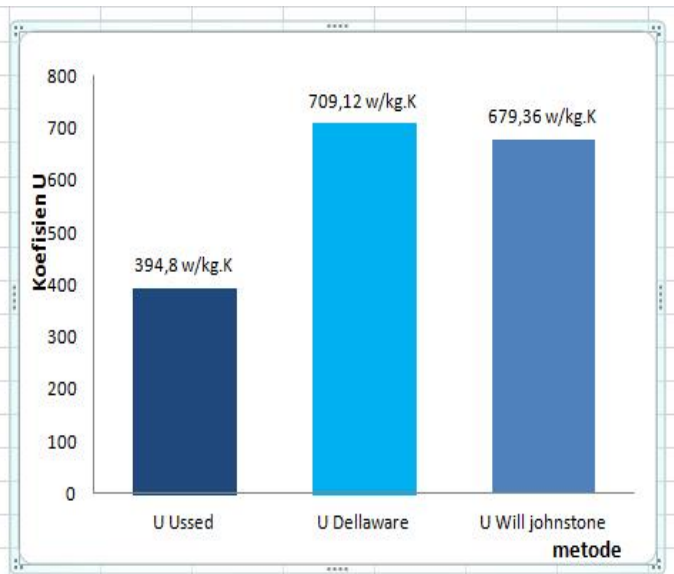

Gambar 13 Kolom perbandingan koefisien perndahan panas total yang terjadi

Dari kolom perbandingan diatas telah dihitung sebelumnya bahwa koefisien

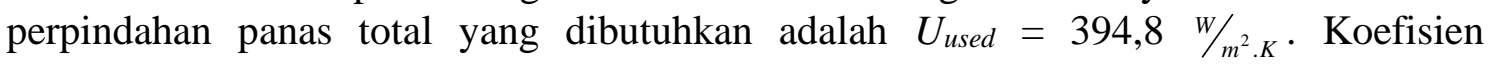
perpindahan panas total dengan metode Delaware lebih besar 79,6\% dinbandingkan $U_{\text {used }}$, sedangkan koefisien perpindahan panas total dengan metode Wills and Johnston lebih besar $72 \%$ dibandingkan $U_{\text {used }}$. Dengan demikian, koefisien perpindahan panas total yang terjadi sudah sesuai dengan kebutuhan.

\section{KESIMPULAN}

1. Hasil perhitungan koefisien perpindahan panas dan penurunan tekanan fluida di dalam shell antara metode Delaware dan metode Wills and Johnston mempunyai perbedaan yang kecil sehingga ke dua metode tersebut dianggap sesuai untuk analisis perpindahan panas pada heat exchanger tipe shell and tube.

2. Koefisien perpindahan panas total dengan metode Delaware $709,12 \mathrm{~W} / \mathrm{m}^{2} . K$ lebih

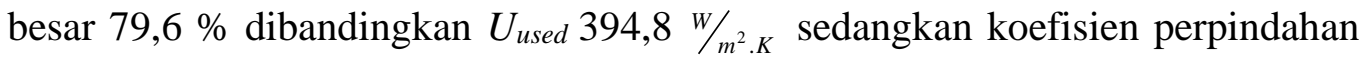
panas total dengan metode Wills and Johnston $679,36 \mathrm{~W} / \mathrm{m}^{2} . K$ lebih besar $72 \%$ di bandingkan $U_{\text {used }}$.

\section{SARAN}

1. Analisa heat exchanger yang telah dilakukan tidak mencakup bagian-bagian yang sangat detail sehingga diperlukan analisa pada komponen-komponen yang lebih detail dan analisis yang lebih mendalam agar diperoleh hasil analisis yang siap difabrikasi dan mempunyai kinerja yang sangat baik.

2. Perlu adanya rumusan yang tepat dalam penentuan jumlah tube pada heat exchanger, karena dalam perhitungan sebelumnya tube dihitung secara manual. 


\section{DAFTAR PUSTAKA}

[1] Richard C.byrne (1988). Tubular Exchanger Manufacture Assoaciation (TEMA) $8^{\text {th }}$ edition. New York.

[2] E U Schlunder ( 2000 ). Heat Exchanger Design Handbook. Marcel Dekker. New York.

[3] Cengel, Y. A. ( 1997 ). Introductions to Thermodynamics and Heat Transfer. New York. Mc. Graw Hill.

[4] Yildiz bayazitoglu. ( 1988 ). Element of Heat Transfer. New York. Mc. Graw Hill.

[5] Warren, M. Rohsenow. ( 1985 ). Hand Book of Heat transfer application $2^{\text {nd }}$ edition. New York. Mc. Graw Hill.

[6] Kakac, Sidic dan Hongtan Liu. (1997). Heat Exchanger, Selection, Rating dan Thermal Design. CRC Press. New York

[7] Kern, D. Q. (1983). Process Heat Transfer $2^{\text {nd }}$. Tokyo . McGrow Hill Book Company Inc. 